J Am Chem Soc. 2016 March 02; 138(8): 2516-2519. doi:10.1021/jacs.5b13376.

\title{
The Hydroxyl Radical is a Critical Intermediate in the Voltammetric Detection of Hydrogen Peroxide
}

\author{
James G. Roberts, Maxim A. Voinov, Andreas C. Schmidt, Tatyana I. Smirnova, and Leslie \\ A. Sombers \\ Department of Chemistry, North Carolina State University, Raleigh, NC 27695, USA.
}

\begin{abstract}
Cyclic voltammetry is a widely used and powerful tool for sensitively and selectively measuring hydrogen peroxide $\left(\mathrm{H}_{2} \mathrm{O}_{2}\right)$. Herein, voltammetry was combined with electron paramagnetic resonance spectroscopy to identify and define the role of an oxygen-centered radical liberated during the oxidation of $\mathrm{H}_{2} \mathrm{O}_{2}$. The spin-trap reagents, 5,5-dimethyl-1-pyrroline N-oxide (DMPO) and 2-ethoxycarbonyl-2-methyl-3,4-dihydro-2H-pyrrole-1-oxide (EMPO), were employed. Spectra exhibit distinct hyperfine patterns that clearly identify the DMPO-OH $\bullet$ and EMPO-OH• adducts. Multiple linear regression analysis of voltammograms demonstrated that the hydroxyl radical is a principal contributor to the voltammetry of $\mathrm{H}_{2} \mathrm{O}_{2}$, as signal is attenuated when this species is trapped. These data incorporate a missing, fundamental element to our knowledge of the mechanisms that underlie $\mathrm{H}_{2} \mathrm{O}_{2}$ electrochemistry.
\end{abstract}

\section{Graphical Abstract}

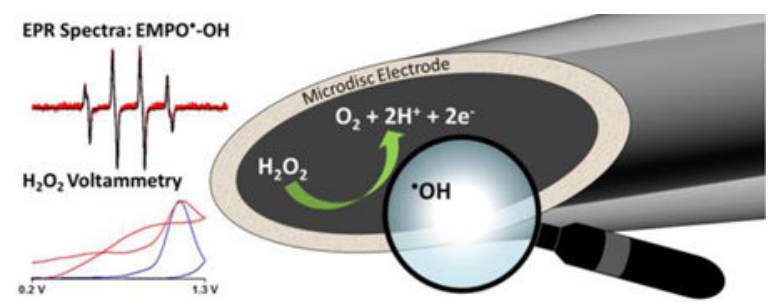

The electrochemical detection of hydrogen peroxide $\left(\mathrm{H}_{2} \mathrm{O}_{2}\right)$ has drawn much attention over several decades because it plays a key role in powerful analytical tools. Most notably, $\mathrm{H}_{2} \mathrm{O}_{2}$ electrochemistry underlies the performance of peroxidase-based biosensors, and thus it is of significant interest to scientists developing technologies for rapid molecular monitoring.

Despite a staggering number of publications on biosensor design, the market is still far from meeting many key end-user needs. This is largely attributed to issues in stability, sensitivity, and accuracy that hinge on the selective and reliable detection of $\mathrm{H}_{2} \mathrm{O}_{2}$ at enzyme-modified electrode surfaces. Even though there is wide interest in exploiting this electrochemistry, the precise mechanisms that describe $\mathrm{H}_{2} \mathrm{O}_{2}$ redox activity at various electrode surfaces are not

Corresponding Author lasomber@ncsu.edu.

ASSOCIATED CONTENT

Supporting Information

Experimental details and data. This material is available free of charge via the Internet at http://pubs.acs.org. 
well understood. Electrochemical oxidation of $\mathrm{H}_{2} \mathrm{O}_{2}$ results in the generation of 2 protons, 2 electrons, and oxygen gas.

$$
\mathrm{H}_{2} \mathrm{O}_{2} \rightleftharpoons 2 \mathrm{H}^{+}+2 e^{-}+\mathrm{O}_{2}
$$

However, this reaction is convoluted by its dependency on the electrode surface, applied potential, electrolyte composition, etc. ${ }^{1}$ Studies have demonstrated that $\mathrm{H}_{2} \mathrm{O}_{2}$ oxidation occurs in the potential region corresponding to oxide film formation, ${ }^{2}$ and it is favored on an oxidized platinum surface. ${ }^{3}$ Thus, a longstanding question is how the oxidized electrode surface influences chemical reactivity. In this work, we use electron paramagnetic resonance (EPR) spectroscopy to identify the hydroxyl radical as a key intermediate species underlying the voltammetric detection of $\mathrm{H}_{2} \mathrm{O}_{2}$ at both platinum and carbon-fiber electrodes. The unexpected data advance our understanding of chemical processes occurring at the electrode surface, and promise further exploitation of $\mathrm{H}_{2} \mathrm{O}_{2}$ electrochemistry in numerous applications.

Figure 1A-B depicts cyclic voltammograms for $100 \mathrm{mM} \mathrm{H}_{2} \mathrm{O}_{2}$ collected using a scan rate of $1 \mathrm{~V} \cdot \mathrm{s}^{-1}$ on a carbon-fiber and platinum microelectrode, respectively. Current density is plotted on the y-axis in order to facilitate a direct comparison. Distinct responses are observed, where anodic current is generated on platinum at a lower potential relative to carbon. We have found that fast-scan cyclic voltammetry (FSCV) is particularly useful for monitoring rapid fluctuations of biological $\mathrm{H}_{2} \mathrm{O}_{2}$ in live tissue, as it enables real-time measurements when coupled with carbon-fiber microelectrodes. ${ }^{4}$ Thus, carbon and platinum electrode materials were also compared using a scan rate of $400 \mathrm{~V} \cdot \mathrm{s}^{-1}$ (Figure 1C-D). On carbon, peak current increased as the positive wavelimit was increased. However, the opposite trend was observed using the platinum electrode, suggesting a critical dependence on the oxidation state of the platinum surface. Oxides accumulate on platinum surfaces upon strong anodic polarization, and these can shift the potential in the positive direction during the descending sweep. ${ }^{2}$ The atypical location of the peak at high scan rates (evident on the reverse scan) is an advantageous consequence of data filtering (Figure S1), ${ }^{5}$ resulting in a predictable and well-resolved signal that allows rapid qualitative identification and accurate quantitation. Additional differences between these materials are evident when investigating the effects of scan rate (Figure S2).

EPR spectroscopy was used to investigate if short-lived radical species are generated in $\mathrm{H}_{2} \mathrm{O}_{2}$ oxidation. Two spin traps, 2-ethoxycarbonyl-2-methyl-3,4-dihydro-2H-pyrrole-1oxide (EMPO) and 5,5-dimethyl-1-pyrroline $\mathrm{N}$-oxide (DMPO), were added to the $\mathrm{H}_{2} \mathrm{O}_{2}$ solution in separate experiments. The spin trap itself remains EPR silent until adduct formation. Figure 2 illustrates reaction paths for two possible oxygen-centered radicals with EMPO and DMPO, and their respective spectra. The left path shows hydroxyl radical addition to the alpha carbon of the spin traps; while the right path illustrates the trapping of a superoxide radical. The resulting spectra demonstrate the qualitative power of EPR spectroscopy. A platinum microelectrode was lowered into a $200 \mu \mathrm{L}$ electrochemical cell with a $\mathrm{Ag} / \mathrm{AgCl}$ reference electrode, and a traditional cyclic waveform was continuously applied for 30 minutes $\left(+0.2\right.$ to $\left.+1.3 \mathrm{~V}, 1 \mathrm{~V} \cdot \mathrm{s}^{-1}\right)$. Continuous wave X-band EPR spectra 
collected for samples that contained both $5 \mathrm{mM} \mathrm{H}_{2} \mathrm{O}_{2}$ and $5 \mathrm{mM}$ EMPO show a clear four line 1:2:2:1 splitting pattern characteristic of the EMPO'-OH adduct (Figure $3 \mathrm{~A}$ ). The experimental EPR spectra were least-squares simulated using a Voigt function with previously described software ${ }^{12,13}$ to yield Species $1: A_{N}=14.11 \pm 0.02 \mathrm{G}, A_{H}=15.00$ $\pm 0.04 \mathrm{G}$ and $\mathrm{A}_{\mathrm{H}}=0.82 \pm 0.03 \mathrm{G}$; Species $2: \mathrm{A}_{\mathrm{N}}=14.02 \pm 0.03 \mathrm{G}$ and $\mathrm{A}_{\mathrm{H}}=12.62 \pm 0.02$ G. ${ }^{6}$ Literature values for the EMPO $-\mathrm{OH}$ adduct are Species $1: \mathrm{A}_{\mathrm{N}}=14.0 \mathrm{G}, \mathrm{A}_{\mathrm{H}}=15.1 \mathrm{G}$ and $A_{H}=0.9 \mathrm{G}$; Species 2: $A_{N}=14.0 \mathrm{G}$ and $A_{H}=12.7$ G. ${ }^{7}$ By contrast, samples that contained only EMPO $\left(\right.$ no $\left.\mathrm{H}_{2} \mathrm{O}_{2}\right)$ resulted in spectra that did not exhibit any discernible signal above noise (Figure 3B). The EPR spin trapping experiments are known to produce adduct artifacts and it can be contended that hydroperoxide radical adducts can rapidly decay to hydroxyl radical adducts, resulting in false identification of the principal radical. ${ }^{8}$ However, EMPO is the most efficient spin trap for the detection of oxygen-centered free radicals. The EMPO--OOH adduct is about five times more stable than the corresponding DMPO adduct, and it does not readily decay to $\mathrm{EMPO}^{\circ}-\mathrm{OH}$, making the experimental data less ambiguous..$^{9}$ No signal characteristic of the EMPO'-OOH adduct was detected in our experiments, allowing us to conclude that the decomposition of the DMPO-OOH adduct is not a source of the observed DMPO-OH adduct (Figure 3C). Additional experiments were carried out using a fast cyclic waveform $\left(+0.2\right.$ to $\left.+1.3 \mathrm{~V}, 400 \mathrm{~V} \cdot \mathrm{s}^{-1}, 100 \mathrm{~Hz}\right)$ at both carbon fiber and platinum microelectrodes. The resulting spectra again show a clear hyperfine splitting pattern characteristic of the hydroxyl radical adduct with no evidence of the hydroperoxide adduct (Figure 3C-D). The hyperfine coupling constants fitted for these data are presented in Table S-1. It is important to note that the absence of an EPR signal for a specific radical species does not prove that it is not transiently formed. Dimethyl sulfoxide (DMSO, 20-fold excess) was added to the solution to selectively scavenge hydroxyl radicals. ${ }^{10}$ The typical four-line spectrum was abolished (Figure S3). As DMSO quenching of the hydroxyl radical generates a methyl radical, the characteristic six-line spectrum for a $\mathrm{DMPO}^{-}-\mathrm{CH}_{3}$ adduct was also expected, but not observed. However, the absence of the methyl adduct does not exclude hydroxyl radical quenching by DMSO. Indeed, similar observations have been reported by others, although under different experimental conditions. 11

Experiments were designed to assess the possibility that the radicals originated at a location other than the working electrode. To investigate the reference electrode, a micro-agar salt bridge was constructed. ${ }^{12}$ This enabled stable potentials and effectively excluded the Ag/ $\mathrm{AgCl}$ reference electrode from the sample. The resulting spectra were identical to those generated using the direct-contact reference (data not shown), verifying that the site of radical formation was not the reference electrode. An oxygen-centered radical could also originate from the supporting electrolyte. Trizma buffer and phosphate buffered saline were compared to uncover any contribution from Trizma (which possesses three terminal hydroxyl groups) on adduct formation, and equivalent spectra resulted for both (data not shown). Additional control experiments included holding the potential $(+0.2 \mathrm{~V})$ without cycling, or allowing the potential of the electrode to float in a solution of $\mathrm{H}_{2} \mathrm{O}_{2}$ and DMPO. The collected spectra resulted in no observable signal (data not shown). To the best of our knowledge this report is the first direct demonstration of hydroxyl radical production in the anodic decomposition of $\mathrm{H}_{2} \mathrm{O}_{2}$. The radical was generated at both platinum and carbon 
electrodes, using a wide range of scan rates, only in the presence of $\mathrm{H}_{2} \mathrm{O}_{2}$. The

hydroperoxide radical was not observed. Hall et al. have proposed that $\mathrm{H}_{2} \mathrm{O}_{2}$ reduces surface oxides and the observed current is generated in the re-oxidation of platinum. ${ }^{1 \mathrm{~b}}$

$$
\begin{aligned}
& \mathrm{Pt}(\mathrm{OH})_{2}+\mathrm{H}_{2} \mathrm{O}_{2} \rightleftharpoons \mathrm{Pt}(\mathrm{OH})_{2} \cdot \mathrm{H}_{2} \mathrm{O}_{2} \\
& \mathrm{Pt}(\mathrm{OH})_{2} \cdot \mathrm{H}_{2} \mathrm{O}_{2} \rightleftharpoons \mathrm{Pt}^{0}+2 \mathrm{H}_{2} \mathrm{O}+\mathrm{O}_{2}
\end{aligned}
$$

Far less is known about the oxidation of $\mathrm{H}_{2} \mathrm{O}_{2}$ on carbon. This process is $\mathrm{pH}$ dependent (Figure S4), demonstrating that $\mathrm{H}^{+}$or $\mathrm{OH}^{-}$ions take part in the electrode reaction. For example, the hydroxyl radical might be generated from $\mathrm{H}_{2} \mathrm{O}_{2}$ as follows:

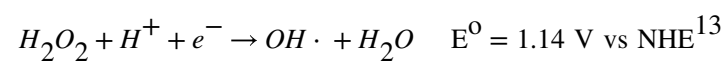

The free energy change for the dissociation of $\mathrm{H}_{2} \mathrm{O}_{2}$ into 2 hydroxyl radicals is $\sim 50 \mathrm{kcal}$ ( $\sim 1.1 \mathrm{~V}$ vs NHE), and the conversion of radicals into $\mathrm{OH}^{-}$ions occurs readily. ${ }^{14}$ Thus, it is energetically feasible that a hydroxyl radical intermediate is generated in the decomposition of $\mathrm{H}_{2} \mathrm{O}_{2}$. Reaction could then take place between a free hydroxyl radical and oxygencontaining groups on the oxidized carbon surface, for example:

$$
\mathrm{CO} \cdots \mathrm{OH}+\mathrm{OH} \cdot \rightleftharpoons \mathrm{C}^{0}+\mathrm{O}_{2}+\mathrm{H}_{2} \mathrm{O}
$$

with current generated in the re-oxidation of carbon.

$$
\mathrm{C}^{0}+2 \mathrm{H}_{2} \mathrm{O}-4 e^{-} \rightleftharpoons \mathrm{CO}_{2}+4 \mathrm{H}^{+}
$$

However, at present these mechanisms are speculative.

Adenosine ${ }^{15}$ and histamine ${ }^{16}$ are other neurochemicals that generate an unusual fast-scan voltammetric signature in which peak current is evident on the reverse scan at approximately $+1.2 \mathrm{~V}$ when using a similar waveform (Figure 4). In order to determine if a peak in this position is generally indicative of a radical intermediate, the trapping experiment was replicated using 5-10 $\mathrm{mM}$ adenosine or $5 \mathrm{mM}$ histamine in solution with $5 \mathrm{mM}$ DMPO, an efficient trap of both nitrogen- and carbon-centered radicals. The adenosine concentration was increased to nearly the solubility limit, to account for the possibility that an adenosineDMPO adduct may have additional hyperfine splitting resulting in reduced signal intensity. ${ }^{17}$ Despite this, the EPR spectra did not exhibit a significant signal over the noise (data not shown). Although this does not absolutely exclude the possibility of radical generation during voltammetry of these molecules, the results suggest that despite similar voltammograms, hydroxyl radical formation is specific to the oxidation of $\mathrm{H}_{2} \mathrm{O}_{2}$.

Activated metal surfaces catalyze the disproportionation of $\mathrm{H}_{2} \mathrm{O}_{2}$ such that bubbles of oxygen form on gold, for example, when exposed to $\mathrm{H}_{2} \mathrm{O}_{2}$ solution. Continuously scanning the electrode serves to activate the surface, and this alone may induce disproportionation of 
$\mathrm{H}_{2} \mathrm{O}_{2}$ and generation of the hydroxyl radical. Thus, experiments were conducted to confirm that it is the electrochemical oxidation of $\mathrm{H}_{2} \mathrm{O}_{2}$ that generates hydroxyl radicals. Using carbon-fiber microelectrodes, voltammograms for $\mathrm{H}_{2} \mathrm{O}_{2}$ were collected in the presence and absence of DMPO in 10-fold excess (Figure 5). DMSO was also tested, at 100-fold excess. ${ }^{18}$ The voltammograms of the spin-trap reagents demonstrate some current (left panels) that is evident in samples containing both the trap and $\mathrm{H}_{2} \mathrm{O}_{2}$ (right panels). Importantly, currents generated for samples containing multiple electroactive species should be additive, such that the sum of the voltammograms for each analyte comprises the voltammogram for the mixed sample. ${ }^{19}$ Current is attenuated, however, if there is a chemical reaction that partially consumes analytes. In these experiments, a summation of current was generally observed, except at $+1.2 \mathrm{~V}$ where the oxidation of $\mathrm{H}_{2} \mathrm{O}_{2}$ is apparent. At this potential, the sum of the currents for the individual analytes exceeds the current observed for the mixture. Since all individual analytes generated predictable currents that increased linearly with respect to concentration, multiple linear regression (MLR) was used to solve for the concentration of $\mathrm{H}_{2} \mathrm{O}_{2}$ in each mixture, ${ }^{20}$ following the equations:

$$
\begin{gathered}
\alpha \cdot(\operatorname{TrapCV})+\beta \cdot\left(\mathrm{H}_{2} \mathrm{O}_{2} \mathrm{CV}\right)=(\text { MixCV }) \\
\frac{\beta}{\delta} \cdot\left(\mathrm{H}_{2} \mathrm{O}_{2} \mathrm{CV}\right)=\left[\mathrm{H}_{2} \mathrm{O}_{2}\right]_{\mathrm{H}_{2} \mathrm{O}_{2} \mathrm{CV}} \\
\text { (2) } \\
\frac{\beta}{\delta}=\left[\mathrm{H}_{2} \mathrm{O}_{2}\right]_{\text {MixCV }}
\end{gathered}
$$

where TrapCV and $\mathrm{H}_{2} \mathrm{O}_{2} \mathrm{CV}$ are normalized voltammograms for each analyte, MixCV is a voltammogram for the mixed analyte solution, $a$ and $\beta$ are coefficients with units of $n A$, and $\delta$ is a calibration factor for each electrode describing sensitivity to $\mathrm{H}_{2} \mathrm{O}_{2}\left(n A \cdot \mu M^{-1}\right)$. The results are presented in Figures 5C-D and listed in Table S-2. The concentration of $\mathrm{H}_{2} \mathrm{O}_{2}$ in both the DMPO- $\mathrm{H}_{2} \mathrm{O}_{2}$ mixture and the DMSO- $\mathrm{H}_{2} \mathrm{O}_{2}$ mixture is significantly less than that measured in samples containing the same concentration of $\mathrm{H}_{2} \mathrm{O}_{2}$ alone. This suggests that the voltammetric detection of $\mathrm{H}_{2} \mathrm{O}_{2}$ directly involves the hydroxyl radical, at both carbon and platinum electrodes. However, it is also possible that the spin trapping reagents reduced electrode sensitivity (fouling). To investigate this, a parallel experiment was performed using $1 \mu \mathrm{M}$ histamine and $1 \mathrm{mM}$ DMPO. Histamine was chosen because its voltammogram exhibits peak current at a comparable potential to that of $\mathrm{H}_{2} \mathrm{O}_{2}$ (Figure 4). MLR predicted equal concentrations of histamine in solutions of histamine and mixed solutions of histamine and DMPO (Table S-3). Thus, electrode sensitivity is not significantly attenuated by spin trap exposure, and the hydroxyl radical plays a fundamental role in the voltammetric detection of $\mathrm{H}_{2} \mathrm{O}_{2}$. 
Overall, these results identify the hydroxyl radical as a key species underlying oxidation of $\mathrm{H}_{2} \mathrm{O}_{2}$ at both carbon and platinum electrode substrates. The direct detection of this chemical intermediate is significant due to broad interest in $\mathrm{H}_{2} \mathrm{O}_{2}$ electrochemistry to serve a variety of purposes, and it promises to inform continued innovation in biosensor development for a range of diagnostic applications across diverse scientific disciplines.

\section{Supplementary Material}

Refer to Web version on PubMed Central for supplementary material.

\section{ACKNOWLEDGMENT}

This research is supported by the National Science Foundation (CHE-1151264). EPR instrumentation was supported by grants from the National Institutes of Health (RR023614), the NSF (CHE-0840501), and NCBC (2009-IDG-1015). Thanks to Steve Feldberg (Brookhaven National Lab) for helpful discussion.

\section{REFERENCES}

(1). (a) Hall SB; Khudaish EA; Hart AL Electrochim Acta 1998, 43, 2015-2024;(b) Hall SB; Khudaish EA; Hart AL Electrochim Acta 1998, 43, 579-588;(c) Hall SB; Khudaish EA; Hart AL Electrochim Acta 1999, 44, 4573-4582.

(2). Hickling A; Wilson WH J Electrochem Soc 1951, 98, 425-433.

(3). (a) Lingane JJ; Lingane PJ Journal of Electroanalytical Chemistry 1963, 5, 411-419;(b) Muller L Journal of Electroanalytical Chemistry 1968, 16, 531-539;(c) Lingane JJ Journal of Electroanalytical Chemistry 1961, 2, 296-309

(4). (a) Sanford AL; Morton SW; Whitehouse KL; Oara HM; Lugo-Morales LZ; Roberts JG; Sombers LA Analytical Chemistry 2010, 82, 5205-10; [PubMed: 20503997] (b) Lugo-Morales LZ; Loziuk PL; Corder AK; Toups JV; Roberts JG; McCaffrey KA; Sombers LA Anal Chem 2013, 85, 8780-6; [PubMed: 23919631] (c) Spanos M; Gras-Najjar J; Letchworth JM; Sanford AL; Toups JV; Sombers LA ACS Chem Neurosci 2013, 4, 782-9. [PubMed: 23556461]

(5). Atcherley CW; Vreeland RF; Monroe EB; Sanchez-Gomez E; Heien ML Anal Chem 2013, 85, 7654-8. [PubMed: 23919317]

(6). (a) Smirnov AI; Belford RL J Magn Reson Ser A 1995, 113, 65-73;(b) Smirnova TI; Smirnov AI; Clarkson RB; Bedford RL J Phys Chem-Us 1995, 99, 9008-9016.

(7). Minotti G; Aust SD J Biol Chem 1987, 262, 1098-104. [PubMed: 3027077]

(8). (a) Finkelstein E; Rosen GM; Rauckman EJ Archives of biochemistry and biophysics 1980, 200, 1-16; [PubMed: 6244786] (b) Finkelstein E; Rosen GM; Rauckman EJ Molecular pharmacology 1982, 21, 262-5; [PubMed: 6285165] (c) Ranguelova K; Mason RP Magnetic Resonance in Chemistry 2011, 49, 152-8. [PubMed: 21246623]

(9). Olive G; Mercier A; Le Moigne F; Rockenbauer A; Tordo P Free Radical Bio Med 2000, 28, 403 408. [PubMed: 10699752]

(10). Voinov MA; Sosa Pagan JO; Morrison E; Smirnova TI; Smirnov AI J Am Chem Soc 2011, 133, 35-41. [PubMed: 21141957]

(11). (a) Eberhardt MK Formation of Reactive Oxygen Metabolites in Vivo. In Reactive Oxygen Metabolites: Chemistry and Medical Consequences; CRC Press: Boca Raton, 2001, p 117;(b) Eberhardt MK. Chemistry of Oxygen-Derived Radicals. In Reactive Oxygen Metabolites: Chemistry and Medical Consequences; CRC Press: Boca Raton, 2001, p 70.

(12). Shao XM; Feldman JL J Neurosci Methods 2007, 159, 108-15. [PubMed: 16916545]

(13). Bard AJ; Parsons R; Jordan J; International Union of Pure and Applied Chemistry. Standard Potentials in Aqueous Solution, 1st ed.; M. Dekker: New York, 1985, p 834.

(14). Bockris JO; Oldfield LF T Faraday Soc 1955, 51, 249-259;Coms FD Ecs Transactions 2008, 16, 235-255.

(15). Ross AE; Venton BJ Analyst 2012, 137, 3045-51. [PubMed: 22606688] 
(16). (a) Chang SY; Jay T; Munoz J; Kim I; Lee KH Analyst 2012, 137, 2158-65; [PubMed: 22416270] (b) Pihel K; Hsieh S; Jorgenson JW; Wightman RM Biochemistry 1998, 37, 1046-52. [PubMed: 9454595]

(17). Bernofsky C; Bandara BM; Hinojosa O; Strauss SL Free Radic Res Commun 1990, 9, 303-15. [PubMed: 2167269]

(18). (a) Dixon WT; Norman ROC; Buley AL J Chem Soc 1964, 3625-3634(b) Lagercrantz C; Forshult S Acta Chem Scand 1969, 23, 811-817.

(19). Bard AJ; Faulkner LR Electrochemical Methods: Fundamentals and Applications, 2nd ed.; John Wiley: New York, 2001, p 833.

(20). (a) Brown SD; Bear RS Crit Rev Anal Chem 1993, 24, 99-131;(b) Bessant C; Saini S J Electroanal Chem 2000, 489, 76-83. 


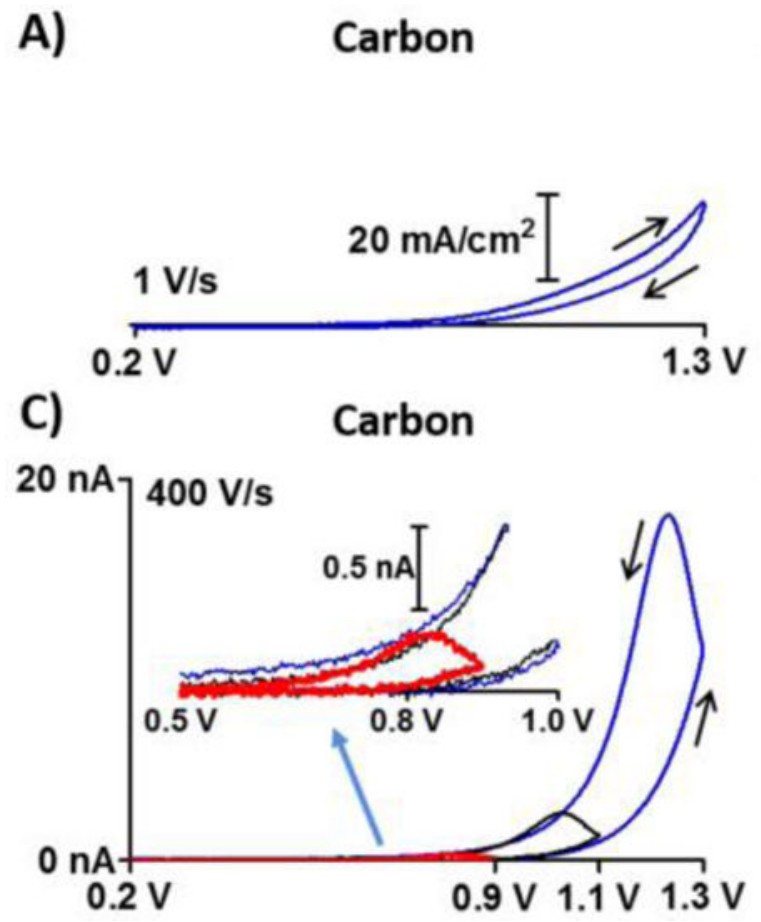

B)

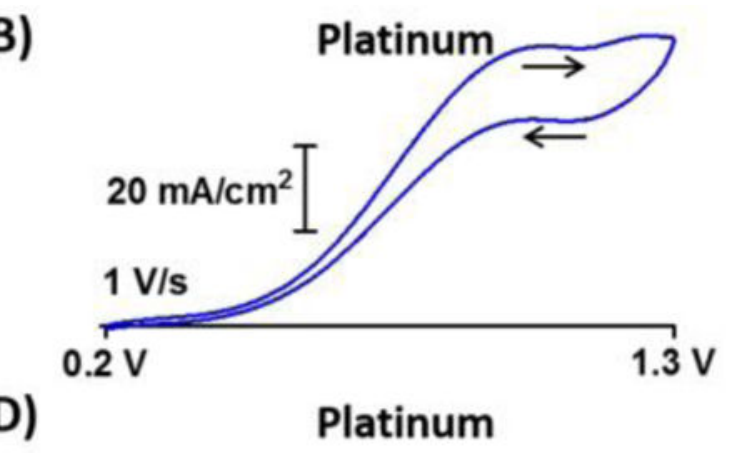

Figure 1.

Representative voltammograms for $100 \mathrm{mM} \mathrm{H}_{2} \mathrm{O}_{2}$ on (A) carbon and (B) platinum electrodes using a scan rate of $1 \mathrm{~V} \cdot \mathrm{s}^{-1}$. Using background subtracted FSCV at $400 \mathrm{~V} \cdot \mathrm{s}^{-1}$, the effects of varying the positive limit are shown for (C) $200 \mu \mathrm{M} \mathrm{H}_{2} \mathrm{O}_{2}$ on carbon and (D) 20 $\mu \mathrm{M} \mathrm{H}_{2} \mathrm{O}_{2}$ on platinum. 

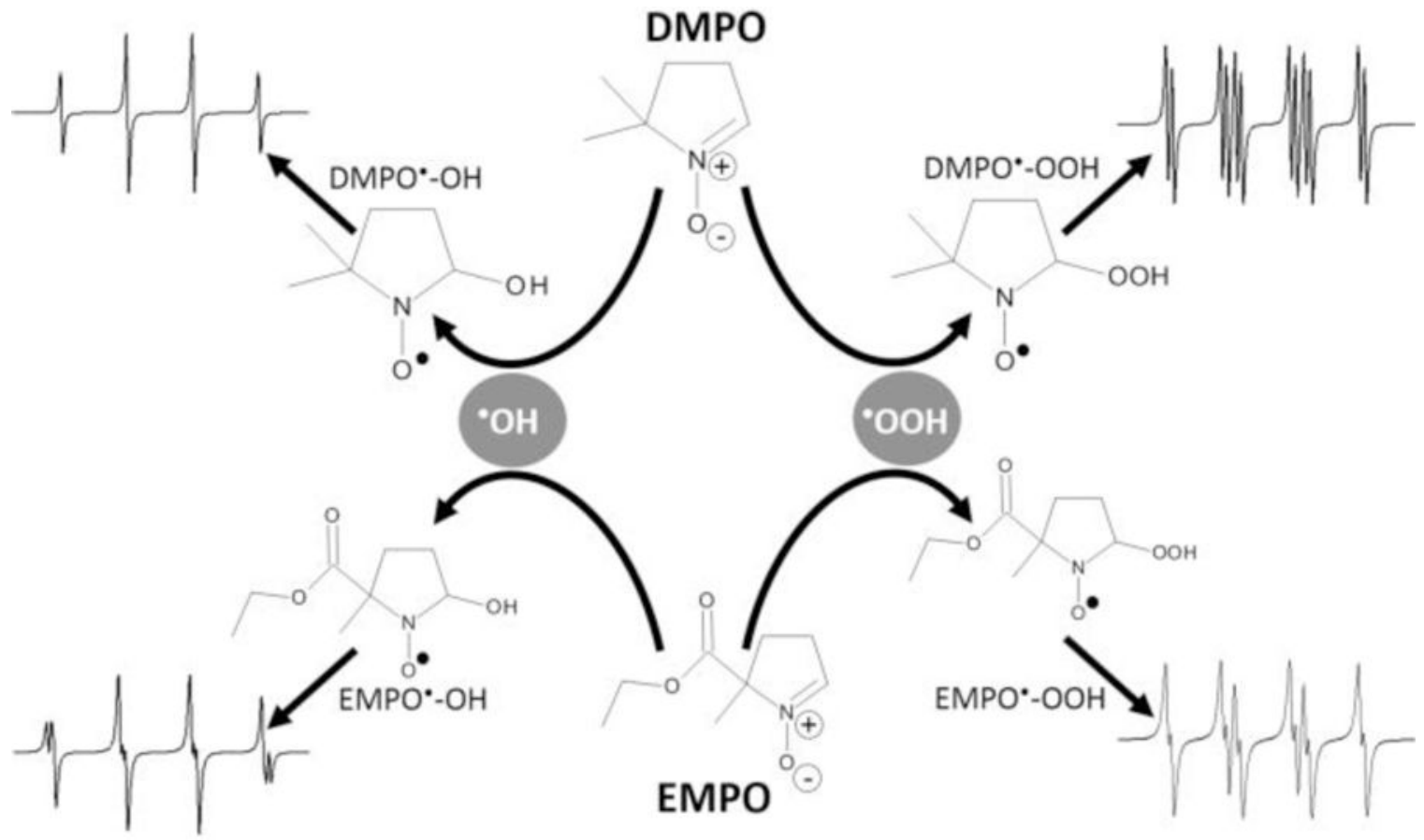

${ }^{\circ} \mathrm{OOH}$
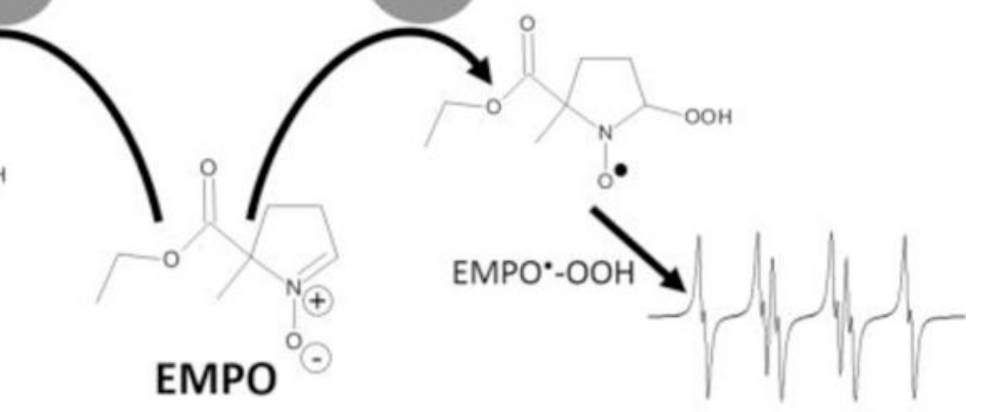

Figure 2.

Suspected trap adducts with respective spectra. 


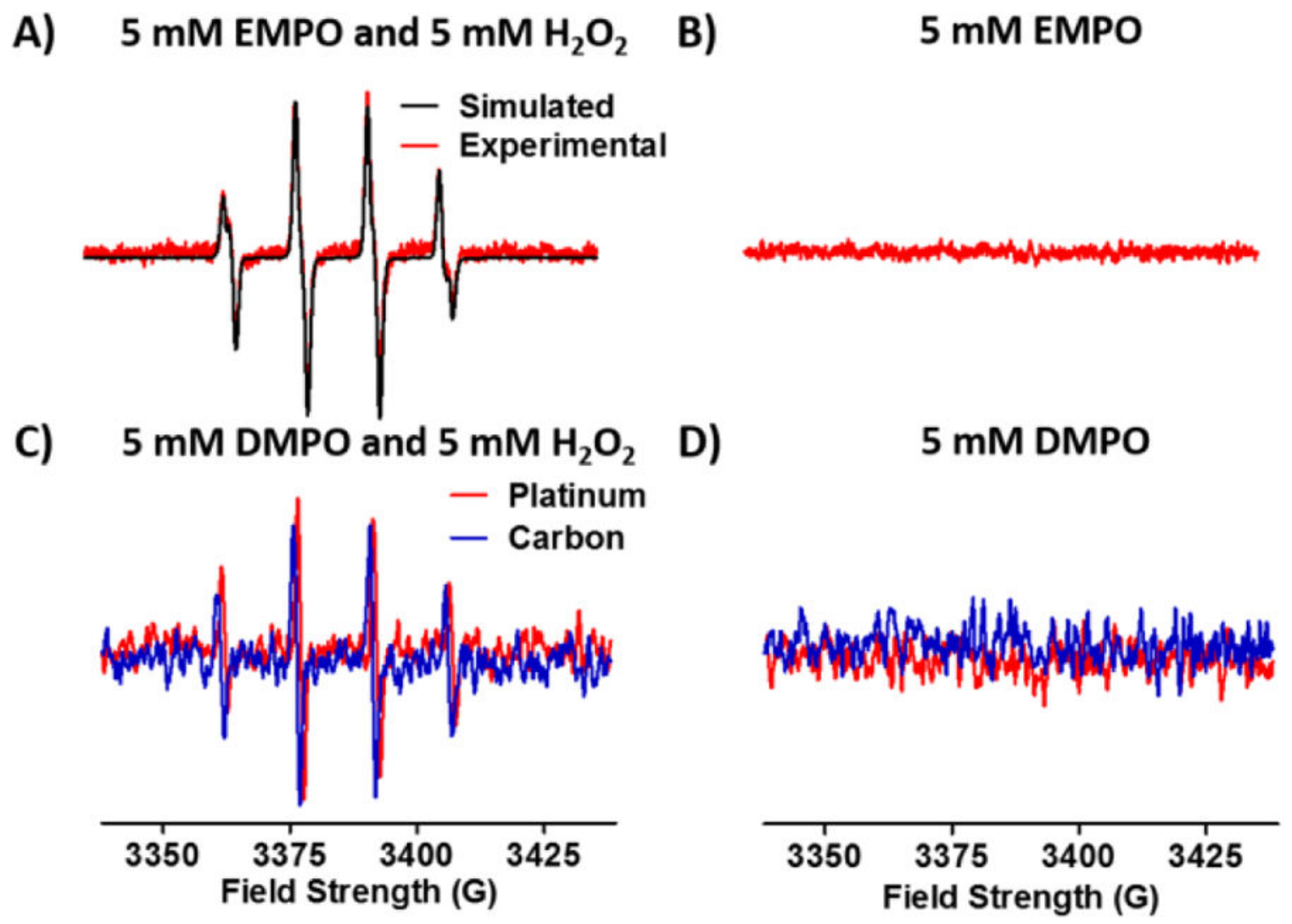

Figure 3.

EPR spectra implicate the hydroxyl radical in the electrochemical oxidation of $\mathrm{H}_{2} \mathrm{O}_{2}$. (A) Platinum electrodes cycled $\left(1 \mathrm{~V} \cdot \mathrm{s}^{-1}\right)$ in the presence of EMPO and $\mathrm{H}_{2} \mathrm{O}_{2}$ generated spectra (red) consistent the simulated spectrum (black). (B) EMPO spectrum in the absence of $\mathrm{H}_{2} \mathrm{O}_{2}$. (C) Spectra generated using carbon (blue) or platinum (red) electrodes $\left(400 \mathrm{~V} \cdot \mathrm{s}^{-1}\right.$ ) for DMPO in the presence and (D) absence of $\mathrm{H}_{2} \mathrm{O}_{2}$. 
A) $5 \mu \mathrm{M}$ Histamine

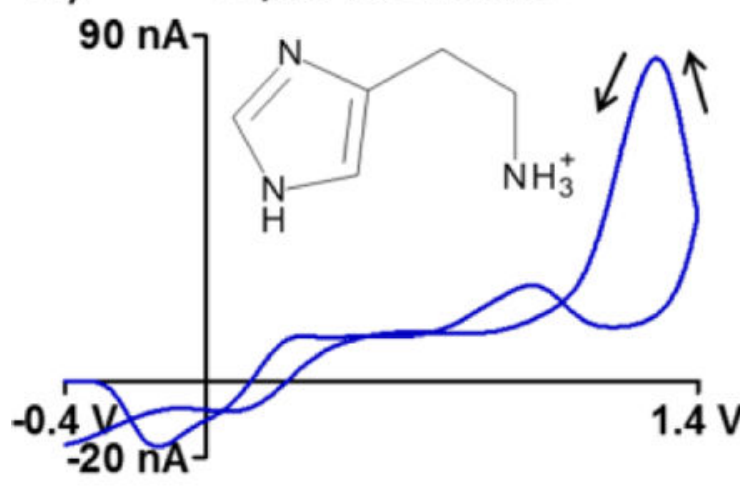

B) B) $5 \mu \mathrm{M}$ Adenosine $60 \mathrm{nA}_{7}$
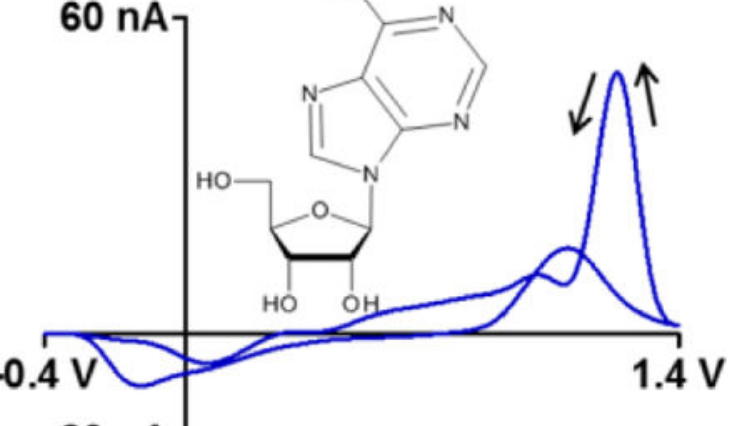
$-20 \mathrm{nA}$

Figure 4.

Representative voltammograms for (A) histamine and (B) adenosine collected on carbonfiber microelectrodes. 

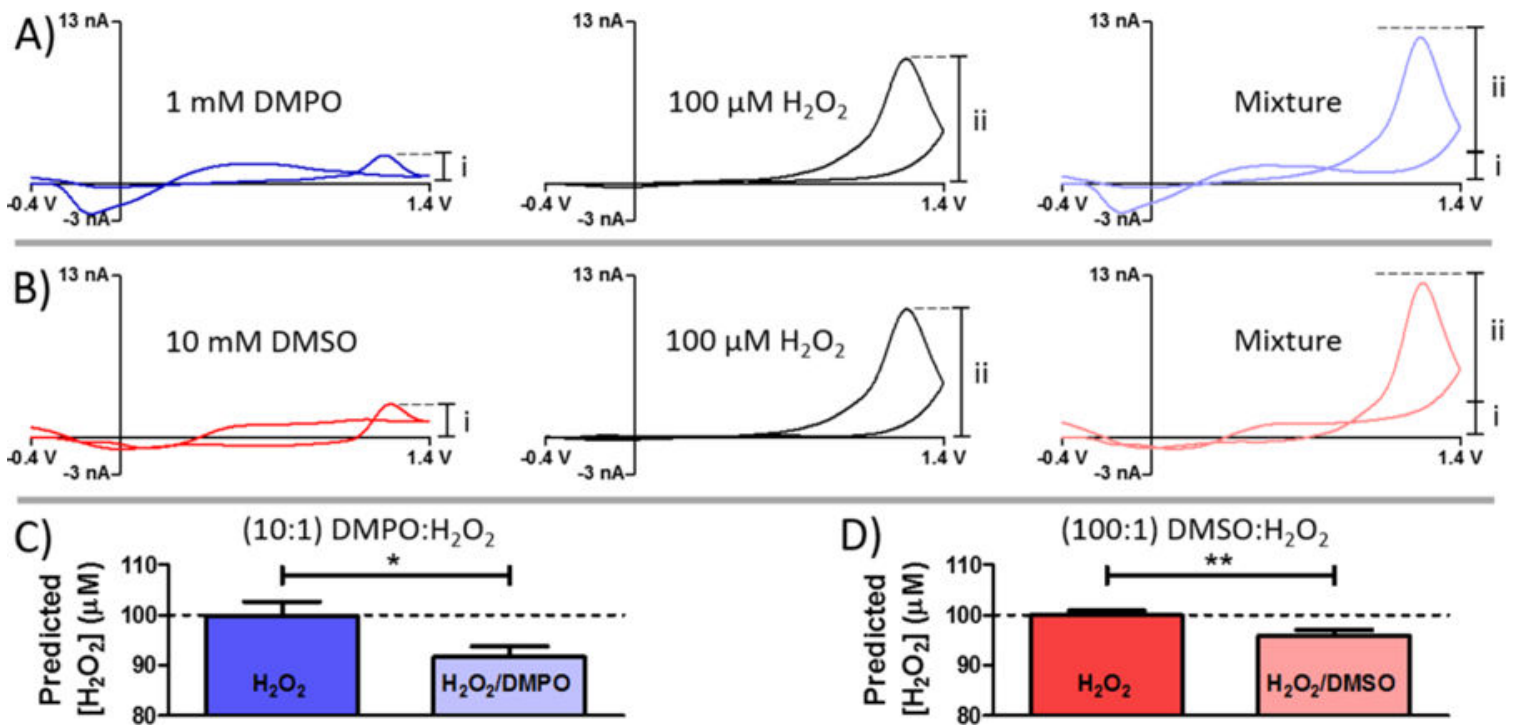

Figure 5.

The electrochemical signal is hydroxyl radical dependent. (A, B) Representative voltammograms (carbon electrodes) for $\mathrm{H}_{2} \mathrm{O}_{2}$, spin trap reagents, and mixtures of the two. (C, D) Incorporation of a spin trap reagent significantly attenuated the signal evident in the electrochemical oxidation of $\mathrm{H}_{2} \mathrm{O}_{2}$. (Student's $t$-test, $\mathrm{p}=0.0150$ and 0.0057 , respectively, $\mathrm{n}$ $=4$ electrodes). 